\title{
Avaliação da substituição do benzeno por ciclohexano como solvente residual na obtenção do álcool etílico absoluto.
}

\author{
Evaluation of the replacement of benzene by cyclohexan as a residual \\ solvent in the obtainment of absolute ethyl alcohol.
}

\author{
Michelle Marina Campos Fonseca ${ }^{1}$, Elis Regina Sousa Morato ${ }^{1}$, Thiago Azevedo de \\ Freitas $^{1}$, Wilson Rodrigues Braz ${ }^{1}$
}

${ }^{1}$ Centro Universitário Uma de Bom Despacho - Curso de Farmácia. Bom Despacho - Minas Gerais, Brasil.

\section{Resumo}

Introdução: O álcool etílico absoluto, também conhecido como álcool puro ou álcool anidro, é obtido pela desidratação do álcool hidratado com o auxílio do benzeno ou substituição deste por ciclohexano. A destilação simples ou fracionada de etanol não resulta em uma concentração alcoólica maior que 95\%. Já o álcool ou etanol absoluto possui uma concentração mínima de 99,6\%. Pertence à classe dos álcoois e, é produzido mais comumente, a partir da cana-de-açúcar ou do milho. Em sua composição, dependendo da rota de síntese, pode conter hidrocarbonetos aromáticos como o benzeno, um composto químico altamente tóxico e carcinogênico. Esse composto é uma das substâncias que desperta grande interesse por ser um solvente presente na formulação de vários produtos de livre acesso a população. $\mathrm{O}$ álcool absoluto é largamente utilizado como matéria-prima para diversos produtos como detergentes, gasolina, no aeromodelismo, preparo de combustível, domissanitários, assepsia das mãos e, principalmente, nas fórmulas farmacêuticas e cosméticas. Objetivo: Avaliação da detecção e quantificação do benzeno e substituição do mesmo por ciclohexano como possível resíduo da rota de síntese de obtenção do álcool absoluto, comercializado em drogarias na região centro-oeste de Minas Gerais, no período de setembro e outubro de 2017. Método: O método utilizado para análise foi o de solventes residuais preconizada pela United States Pharmacopeial Convention, USP $40 \mathrm{NF} 35$, página 2616, por meio da técnica de cromatografia gasosa. Conclusão: Todas as amostras testadas apresentaram teor no teste de cromatográfica gasosa em conformidade com os parâmetros exigidos pela ANVISA. As amostras dos fabricantes se apresentaram seguras ao uso humano em relação a concentração do benzeno e foi comprovada a utilização do ciclohexano no processo de desidratação do álcool.

Palavras-chave: Benzeno; Toxicidade; Ciclohexano; Álcool etílico absoluto.

\section{Autora correspondente:}

Michelle Marina Campos Fonseca 


\section{Abstract}

Introduction: Absolute ethyl alcohol, also known as pure alcohol or anhydrous alcohol, is obtained by dehydrating the hydrated alcohol with the aid of benzene or replacing it with cyclohexane. Simple or fractional distillation of ethanol does not result in an alcoholic concentration greater than $95 \%$. Alcohol or absolute ethanol has a minimum concentration of 99.6\%. It belongs to the class of the alcohols, being from the sugar cane or the corn the two most common forms of being produced. In its composition, depending on the route of synthesis, it may contain aromatic hydrocarbons such as benzene, a highly toxic and carcinogenic chemical compound. This compound is one of the substances which arouses great interest as it is a solvent present in the formulation of various products of free access to the population. Absolute alcohol is widely used as a raw material for various products such as detergents, gasoline, aeromodelling, fuel preparation, household cleaning products, hand hygiene, and mainly in pharmaceutical and cosmetic formulas. Objective: To evaluate the detection and quantification of benzene and its substitution by cyclohexane as a possible residue of the absolute alcohol synthesis route commercialized in drugstores in the central-western region of Minas Gerais during the period of September and October 2017. Method: The method used for analysis was that of residual solvents recommended by the United States Pharmacopeial Convention, USP 40 NF 35, page 2616, by the gas chromatography technique. Conclusion: All the samples tested presented gas chromatographic test content in accordance with the parameters required by ANVISA. The samples of the manufacturers were safe for human use in relation to the benzene concentration and the use of cyclohexane in the alcohol dehydration process was proven.

Keywords: Benzene; Toxicity; Cyclohexane; Absolute ethyl alcohol.

\section{Introdução}

O álcool etílico absoluto é produzido a partir da cana-deaçúcar, no Brasil e, nos Estados Unidos, utiliza-se o milho. Quanto à produção de etanol, o Brasil responde por 35\% da produção mundial, fica atrás somente dos Estados
Unidos, que responde por $37,5 \% .^{1} \mathrm{O}$ processo de produção de álcool no Brasil por meio da cana-de-açúcar envolve basicamente as etapas de moagem, produção do melaço, fermentação e destilação ${ }^{2}$ (FIGURA 1).

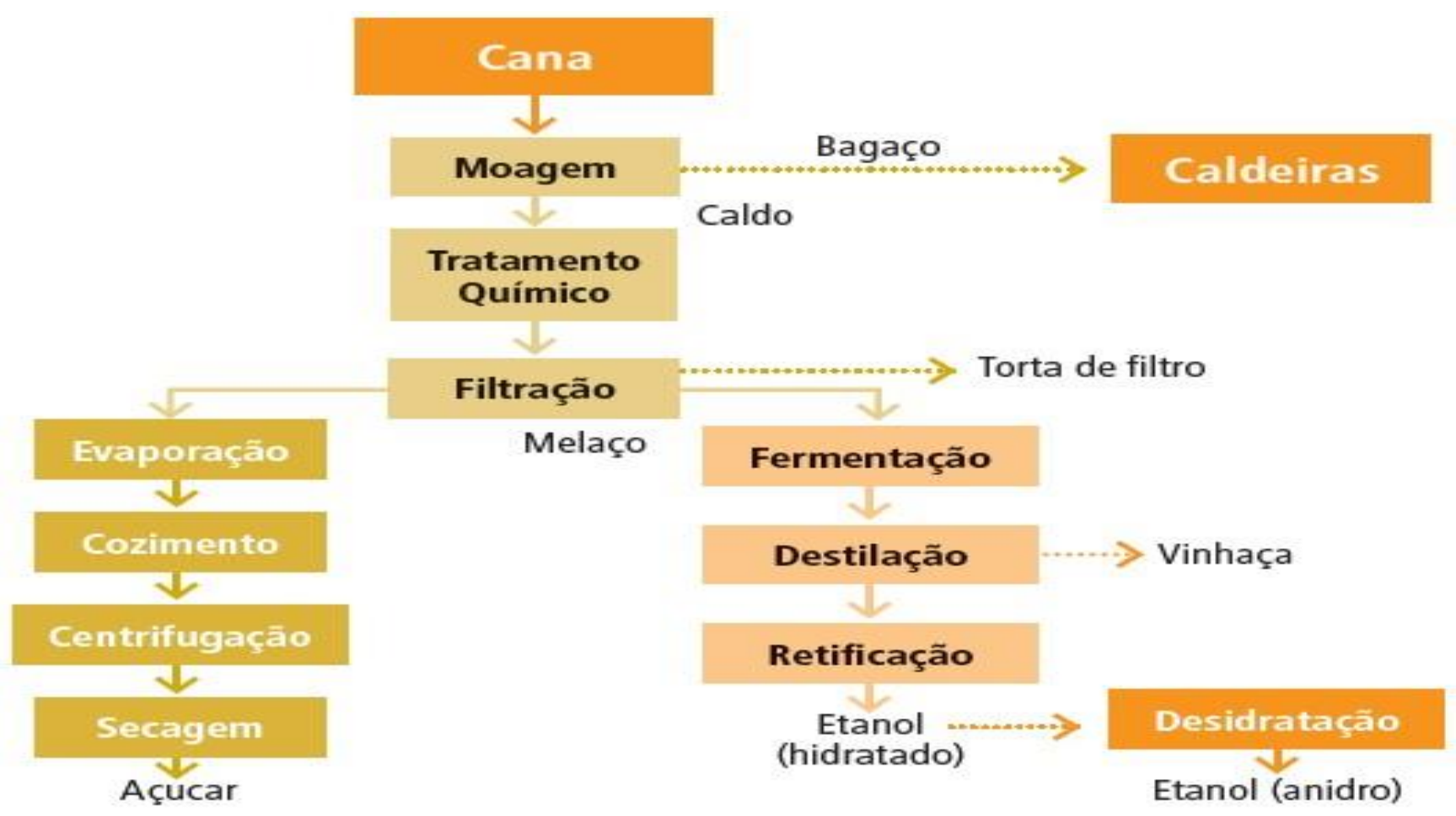

FIGURA 1 - Fluxograma da produção de açúcar e etanol de cana. Fonte: Adaptado de Seabra, $2008 .^{3}$ 
Das etapas apresentadas na FIGURA 1, a etapa de desidratação é a que vai determinar o grau de pureza do etanol. Na obtenção do álcool hidratado a $96^{\circ} \mathrm{GL}$, o processo é realizado em três colunas, a primeira coluna é a fase rica em benzeno, retornando à coluna com adição de uma nova carga; outra fase rica em $\mathrm{H}_{2} \mathrm{O}$ é injetada em uma segunda coluna de destilação, na qual o destilado continua por ser um azeótropo ternário remetido ao separador de fases da primeira coluna; enquanto o produto de fundo, uma solução aquosa de etanol, é enviado para a coluna de destilação que produz o azeótropo binário etanol $96 \%$ e $4 \%$ de água (FIGURA 2).

\section{Desidratação com benzeno}

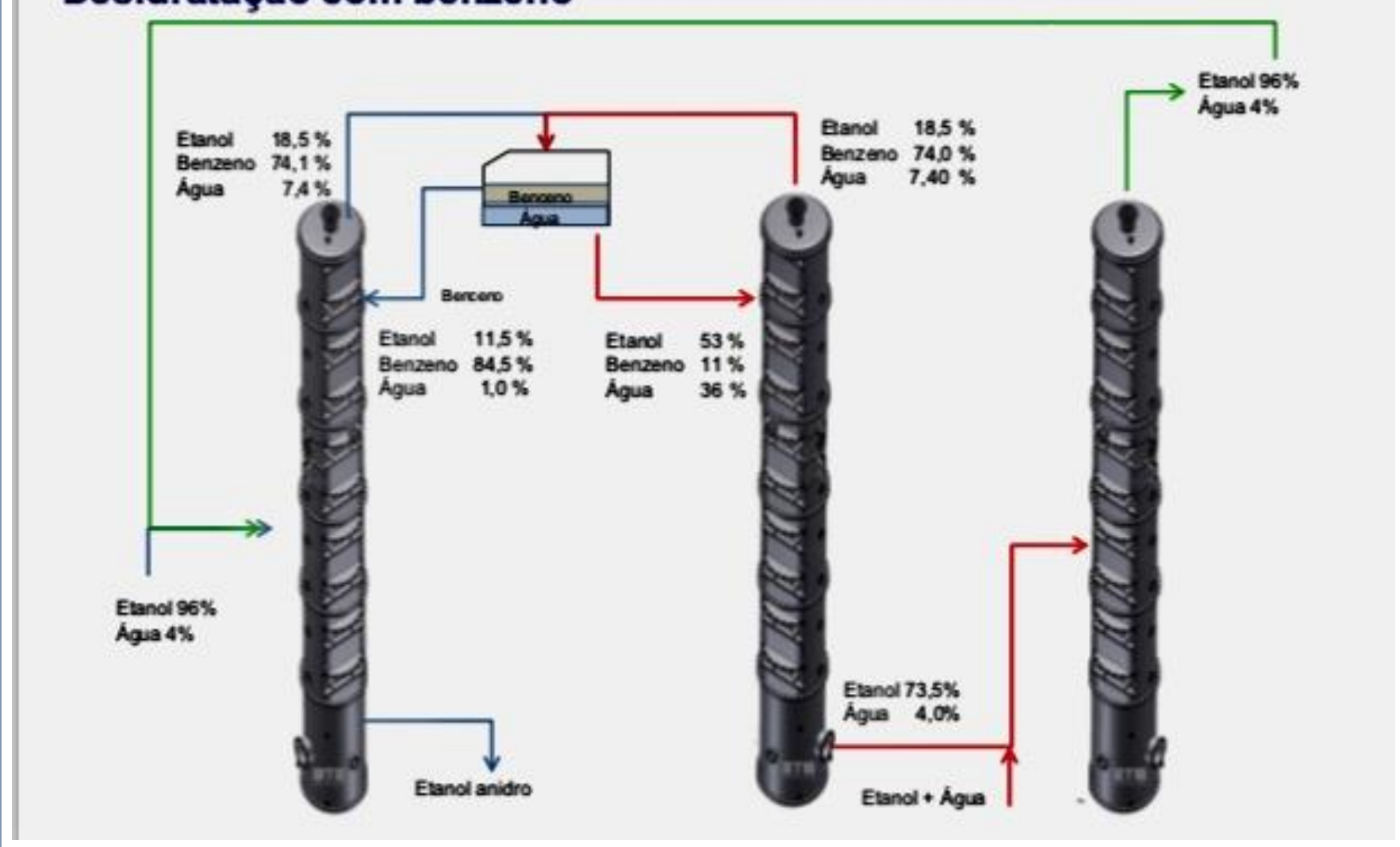

FIGURA 2 - Processo de desidratação com benzeno. Fonte: EEL - USP, 2014. ${ }^{4}$

Em um outro processo para obtenção do álcool etílico absoluto $99,5^{\circ} \mathrm{GL}$, a desidratação é realizada a partir do álcool hidratado $96^{\circ} \mathrm{GL}$ retirando a água residual e aumentando o grau de pureza. ${ }^{5}$

A partir dessas etapas, o álcool pode ser utilizado como combustível, bebida alcoólica, adjuvante farmacêutico, cosméticos (demaquilantes, desodorantes), domissanitários, tintas, vernizes, assepsia das mãos e alcoolquímicas (polímeros). Contudo a Portaria Interministerial $\mathrm{n}^{\circ} 03$, de 28 de abril de 1982, proíbe a comercialização de produtos acabados que contenham benzeno em sua composição, admitindo, porém, alguns percentuais. ${ }^{6,7}$ Pois os solventes residuais desses produtos como, por exemplo o benzeno, podem ser maléficos à saúde.

O álcool etílico absoluto possui em sua rota de síntese o composto benzeno como uma possível substância residual, este um hidrocarboneto aromático $\left(\mathrm{C}_{6} \mathrm{H}_{6}\right)$ (FIGURA 3) é uma substância orgânica volátil e altamente tóxica, principalmente quando o ser humano entra em contato crônico com produtos que tenham em sua composição quantidades superiores ao limite desse solvente. 

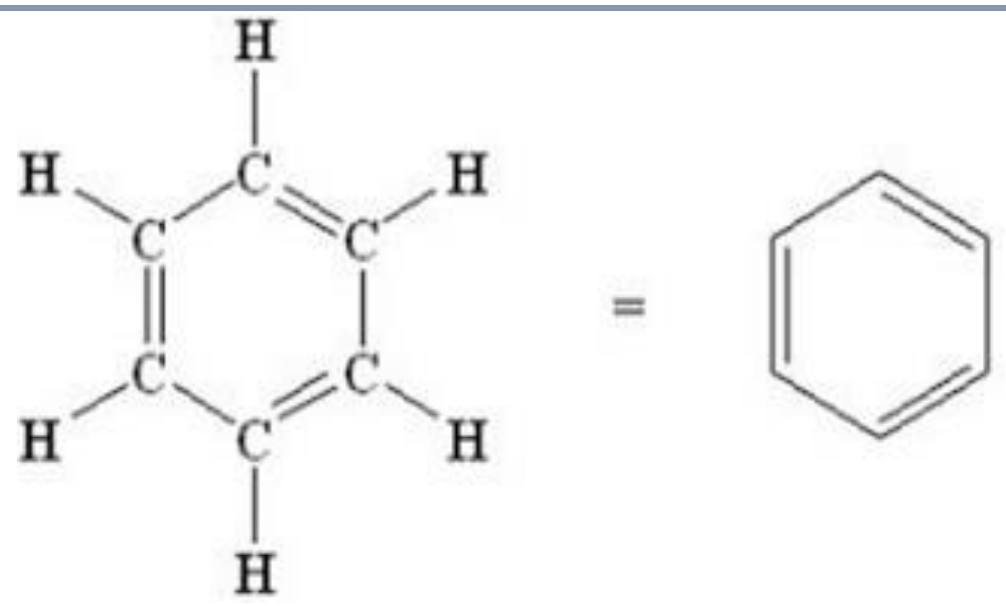

FIGURA 3 - Fórmula estrutural do benzeno. Fonte: Vollhardt; Schore, 2013, p. 627. ${ }^{8}$

O benzeno é constituinte do petróleo, utilizado como solvente em laboratórios químicos (analíticos e de sínteses), como matéria-prima nas indústrias químicas. Tem ponto de fusão a $5,5{ }^{\circ} \mathrm{C}$, ebulição $80{ }^{\circ} \mathrm{C}$ e densidade de $0,87 \mathrm{~g} / \mathrm{cm}^{3}$. É encontrado nos parques petroquímicos, no refino de petróleo, nas companhias siderúrgicas, nas usinas de álcool anidro e na gasolina. ${ }^{9}$ A fumaça do cigarro, vulcões e queimadas de florestas, fontes naturais desse composto, contribuem para sua presença no meio ambiente. ${ }^{10}$

A toxicidade do benzeno independe da via de introdução, uma vez que a principal via de intoxicação ocorre pela inalação dos seus vapores. A absorção via contato dérmico do benzeno na forma gasosa contribui muito pouco para o total da exposição, no entanto, a absorção na forma líquida é considerada uma rota importante. ${ }^{11} \mathrm{O}$ grande problema é que a vítima só percebe a presença desse composto em uma concentração acima de $12 \mathrm{mg} / \mathrm{L}\left(0,04 \mathrm{~g}\right.$ de benzeno por $\mathrm{m}^{3}$ de ar), quando o odor característico da substância é identificado pelo olfato. A toxicidade dos aromáticos é medida em dose letal 50 (DL50) que relaciona a quantidade de substância por quilo do peso da vítima, uma vez que a gravidade da intoxicação depende também da natureza do composto químico. O contato humano com esse composto tem sido uma preocupação desde o século IX, por causar depressão do sistema nervoso central. Há ainda o fato de ser considerado carcinogênico humano por organizações como International Agency of Research of the Cancer (IARC) e a Enveronmental Protection Agency. ${ }^{12,13}$

Nesse contexto, o contato humano com o benzeno pode ser facilitado pelo uso do álcool, já que é largamente utilizado por possuir propriedades microbicidas. É imprescindível, na realização de ações simples de prevenção como a antissepsia das mãos, ${ }^{14}$ a desinfecção do ambiente e de artigos médico-hospitalares. Há, ainda, a questão de o álcool absoluto ser de fácil acesso, por ser comercializado em drogarias, farmácias e supermercados, sem restrições de venda. ${ }^{15}$ Qualquer pessoa pode ter acesso, e pode fazer uso sem controle médico como agente antisséptico, além de ser adquirido com baixo custo e ter fácil aplicabilidade. De forma a minimizar a exposição do benzeno via utilização do álcool etílico, a Agência Nacional de Vigilância Sanitária (ANVISA) limita em sua constituição uma quantidade limite de benzeno de $2 \mathrm{mg} / \mathrm{L} .{ }^{15}$

Quanto à regulação da utilização desse composto, a ANVISA, por meio da RDC n ${ }^{\circ} 53$, de 4 de dezembro de 2015, estabelece parâmetros para a notificação, identificação e qualificação de produtos de degradação e resíduos em medicamentos com substâncias ativas sintéticas e semissintéticas, classificados como novos, genéricos e similares. ${ }^{16}$ Já a RDC no 252 , de 16 de setembro de 2003, determina parâmetros quantitativos mínimos e máximos para a composição de benzeno para produtos e serviços que envolvam riscos à saúde pública bem como às providências a serem tomadas em função dessa composição. ${ }^{17}$ Há, ainda, o destaque para a RDC $\mathrm{n}^{\circ}$ 166, de 24 de Julho de 2017, que dispõe sobre a validação de métodos analíticos e dá outras providências. ${ }^{18}$

A substituição do benzeno por solventes com toxicidade mais baixa como ciclohexano traz mais segurança para saúde do consumidor final, tendo em vista que ele é um solvente classe 2, com um limite de exposição recomendado maior que o benzeno $3885 \mathrm{mg} / \mathrm{L}$, onde o IPVS não é relevante. ${ }^{26}$

No Brasil, já existem novas técnicas de destilação como o uso de peneiras moleculares ou até mesmo a substituição do benzeno como solvente, o que, de certa forma, faz com que esse risco fique cada vez menor, ${ }^{5}$ levando ao consumidor final um produto com menor risco de exposição e contaminação tanto humana quanto ao solo. Porém as indústrias produtoras do álcool, em sua maioria, continuam aplicando o benzeno no processo de destilação devido ao seu baixo custo 
Diante da necessidade de controle da composição do benzeno para atender a legislação apresentada, destacase uma das principais técnicas para detectar resíduos voláteis, que é a cromatografia gasosa (CG) por injeção direta, devido a sua precisão e otimização dos resultados. ${ }^{19}$

Nesse contexto, o objetivo do presente estudo foi analisar o teor de benzeno residual proveniente da rota de síntese do álcool etílico absoluto e sua substituição por ciclohexano no processo de desidratação do álcool, comercializado na região centro-oeste de Minas Gerais, comparando os resultados com os parâmetros exigidos.

\section{Metodologia}

Visto que este trabalho objetiva a detecção de benzeno e ciclohexano determinando quantificação de benzeno proveniente da rota de síntese do álcool etílico absoluto, seguiu-se a metodologia de solventes residuais preconizada pela United States Pharmacopeial Convention (USP), 40 NF 35, v. II, p. 2.616, Alcoohol Dehydrated. ${ }^{20}$

Limpeza de materiais

Todas as vidrarias utilizadas no procedimento experimental foram previamente lavados com detergente neutro, enxaguados com água para injetáveis (WFI) e colocados em estufa, a $100{ }^{\circ} \mathrm{C}$ por uma hora, no intuito de eliminar uma possível contaminação por compostos voláteis.

Os materiais volumétricos, como balões e pipetadores utilizados no procedimento foram calibrados por laboratório acreditado pele Rede Brasileira de Calibração (RBC).

A limpeza dos materiais é imprescindível para se obter um bom resultado analítico, ter todo o material livre de interferente é garantia de confiabilidade e maior proximidade da exatidão. ${ }^{21}$

Preparo de padrões

Para validar o método de escolha foram feitas 18 injeções de padrões em diluições diferentes e 15 injeções em triplicata para determinar a especificidade. Foi preparada a solução estoque a $40 \mathrm{mg} / \mathrm{L}$, adicionando um padrão primário USP standard de benzeno $10.2 \mathrm{mg} / \mathrm{ml} \mathrm{a}$ um padrão secundário de álcool etílico absoluto P.A Sigma Aldrich 99,6\%. Para avaliação do ciclohexano, foi preparada uma solução a $3880 \mathrm{mg} / \mathrm{L}$ utilizando o padrão secundário de ciclohexano Merck P.A $99,9 \%$ e como diluente foi utilizado o padrão álcool etílico absoluto P.A Sigma Aldrich 99,6\%.

A partir da solução estoque, foram feitas diluições para construção da curva de calibração, exatidão e precisão para benzeno. Foram realizadas análises do branco (solventes utilizados para diluir as amostras), contaminados com padrão primário de benzeno padrão secundário de ciclcohexano e das amostras de dois fabricantes distintos em triplicata.

\section{Amostras}

A escolha dos fabricantes e cidades da região centro-oeste de Minas Gerais para a aquisição do álcool foi realizada por amostragem aleatória simples a fim de garantir uma imparcialidade em relação à amostragem. Das 56 cidades do centro-oeste mineiro, sete cidades foram inicialmente selecionadas, quais sejam, Bom Despacho, Divinópolis, Lagoa da Prata, Moema, Nova Serrana, Pará de Minas e Santo Antônio do Monte. Destas cidades inicialmente selecionadas, recensearam-se várias drogarias, onde fizeram parte do sorteio final 23 delas para escolha dos estabelecimentos a serem amostrados. As cidades sorteadas foram mantidas em sigilo bem como os estabelecimentos e duas marcas adquiridas para a pesquisa, a fim de garantir a integridade dos participantes.

\section{Análise cromatográfica}

Para as análises cromatográficas, foi utilizado um cromatógrafo gasoso Agilent 7890B, equipado com o amostrador líquido automático 7693A. O amostrador, abastecido pelos frascos (vial) contendo as soluções identificadas, à caneta, com o nome da solução e sua concentração, foi colocado no injetor do aparelho. Depois de configurar o método, deu-se início às injeções. O tempo de injeção foi de 40 minutos para cada vial e, após o tempo de injeções total dos analitos, foram realizadas as análises dos cromatogramas.

\section{Coluna}

A coluna utilizada nesta pesquisa foi uma coluna capilar Agilent $0.32 \mathrm{~mm}$ por $30 \mathrm{~m} \mathrm{e} 1,8 \mu$. A fase estacionária da coluna é equivalente a G43 e composta por sílica fundida. Essa coluna é empregada para detectar solventes orgânicos voláteis.

Injetor

A temperatura utilizada no injetor foi de $270{ }^{\circ} \mathrm{C}$ e foi utilizado um gás de arraste, o gás Hélio, que é inerte 
com pureza de 99,995\% com fluxo de $35 \mathrm{~cm} / \mathrm{s}$, para realizar a separação das substâncias voláteis.

Detector

Para a realização da pesquisa, foi utilizado o detector de ionização em chama (DIC), a uma temperatura de $280{ }^{\circ} \mathrm{C}$ e o combustível para a chama foi o hidrogênio com $99,995 \%$ de pureza.

Forno

A condição utilizada no forno para ocorrer uma boa separação dos picos foi a temperatura inicial de $40{ }^{\circ} \mathrm{C}$ por 12 minutos, elevando a temperatura em escala de 10 ${ }^{\circ} \mathrm{C}$ por minuto.

Tratamento dos resultados

A integração dos picos cromatográficos foi feita automaticamente no software Openlab, que gerencia o cromatógrafo gasoso. Os valores obtidos das áreas foram colocados em uma planilha eletrônica Microsoft ${ }^{\circledR}$ Excel®, ajustada com as equações que determinam os resultados dos testes, baseados na equação da curva de calibração.
Curva de calibração

A metodologia para quantificação do benzeno foi baseada na metodologia de solventes residuais preconizada pela (USP), 40 NF 35, v. II, p. 2.616, Alcoohol Dehydrated. ${ }^{20}$

O padrão primário de benzeno foi obtido em uma indústria farmacêutica. Avaliou-se a linearidade do método por meio de uma curva de calibração utilizando soluções padrões de benzeno nas concentrações $2 \mathrm{mg} / \mathrm{L}$, 2,4 mg/L, 1, 6 mg/L,1,2 mg/L, 0,8 mg/L, 0,4 mg/L e 0,2 $\mathrm{mg} / \mathrm{L}$. A equação da reta e o coeficiente de correlação linear foram obtidos com auxílio do software Microsoft Excel $^{\circledR}$.

\section{Resultados e discussão}

Curva de Calibração, precisão e exatidão

No intuito de validar a linearidade do método de quantificação de benzeno e ciclohexano, as curvas de calibração (GRÁFICOS 1 e 2) foram construídas utilizando sete pontos de concentração, demonstrando a resposta do método de acordo com a proporcionalidade embasado na RDC 166, de 24 de julho de 2017. ${ }^{21}$

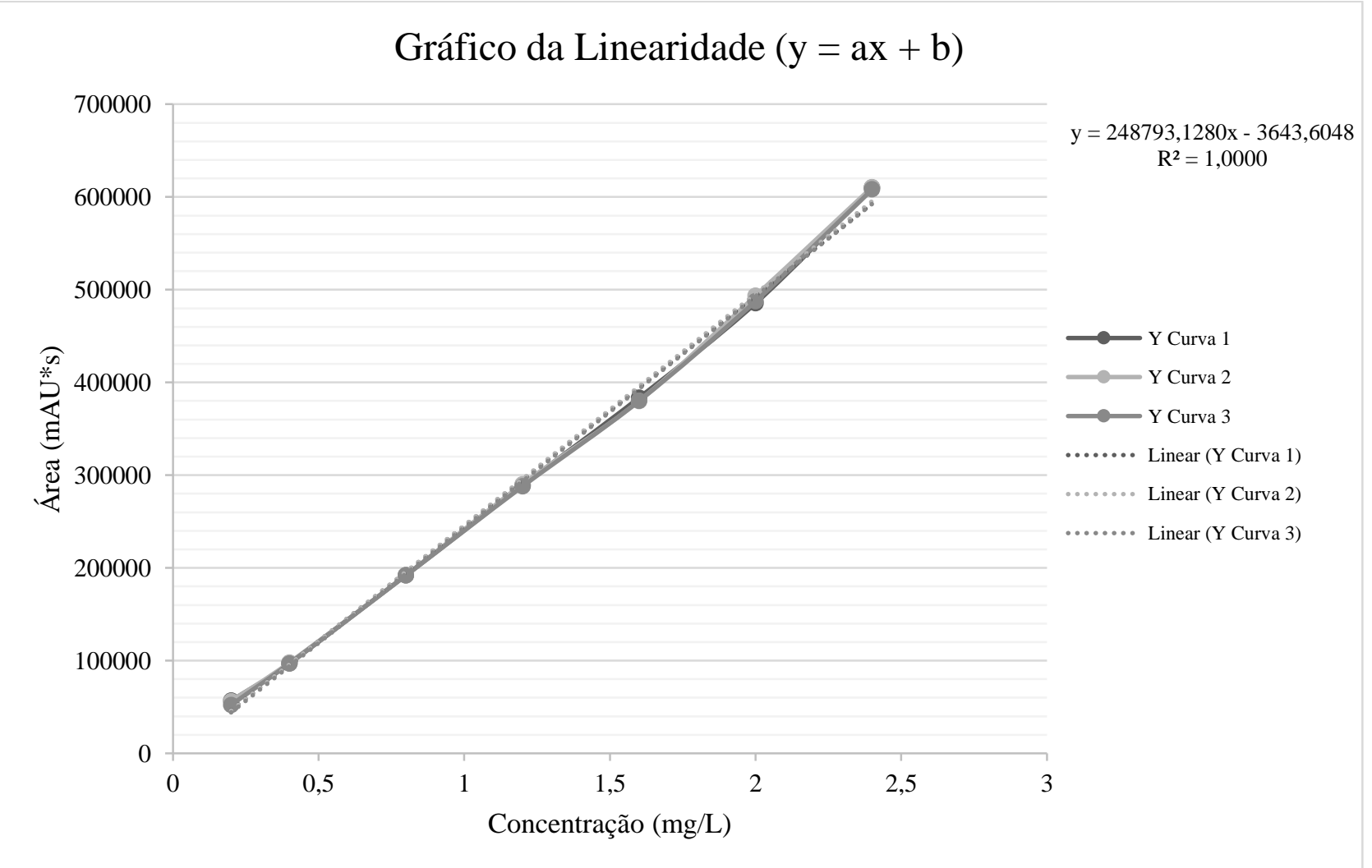

GRÁFICO 1 - Curva de calibração do método para quantificação de benzeno. Fonte: Autores, 2017. 


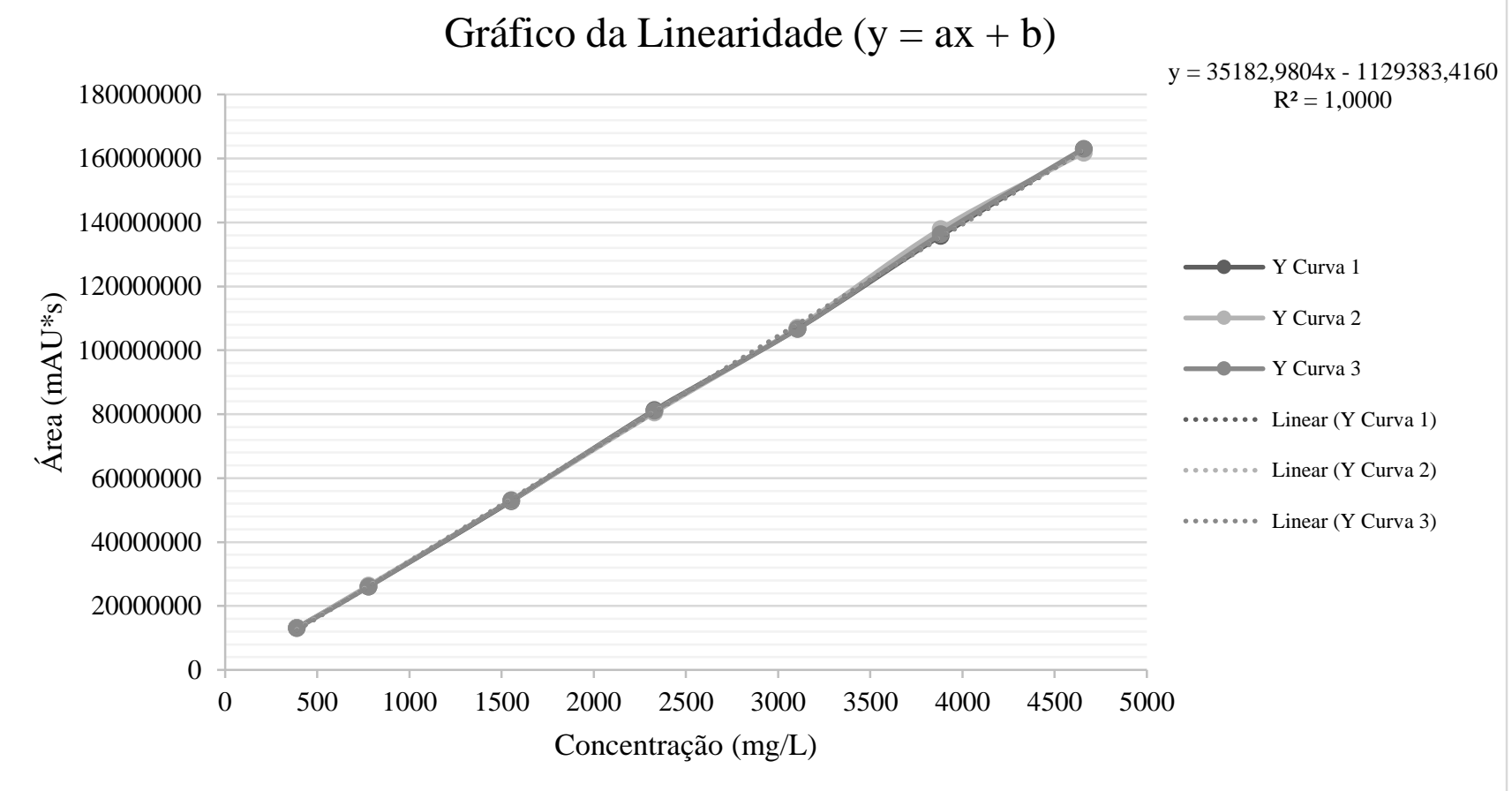

GRÁFICO 2 - Curva de calibração do método para quantificação de ciclohexano. Fonte: Autores, 2017.

As TABELAS 1 e 2, a seguir, apresentam os valores obtidos no ensaio que subsidiaram as curvas de calibração, bem como seus desvios e médias.

TABELA 1 - Tabela de valores das áreas da curva de calibração, desvio padrão, desvio padrão relativo e média para o benzeno.

\begin{tabular}{cccccccc}
\hline \multicolumn{70}{|c}{ Linearidade } \\
\hline $\begin{array}{c}\text { Concentraçăo } \\
\text { (\%) }\end{array}$ & $\begin{array}{c}\text { Concentraçāo } \\
\mathrm{mg} / \mathrm{L}\end{array}$ & $\begin{array}{c}\text { Curva 1 } \\
\text { Área }\end{array}$ & $\begin{array}{c}\text { Curva 2 } \\
\text { Área }\end{array}$ & $\begin{array}{c}\text { Curva 3 } \\
\text { Área }\end{array}$ & Média & DP & DPR (\%) \\
\hline 10.00 & 0.2 & 56669 & 56253 & 52164 & 55029 & 2489.5783 & 4.5241 \\
20.00 & 0.4 & 97001 & 97821 & 96801 & 97208 & 540.4936 & 0.5560 \\
40.00 & 0.8 & 192034 & 191998 & 191821 & 191951 & 114.0132 & 0.0594 \\
60.00 & 1.2 & 288956 & 290248 & 287845 & 289016 & 1202.6356 & 0.4161 \\
80.00 & 1.6 & 383557 & 379885 & 380057 & 381166 & 2072.1634 & 0.5436 \\
100.00 & 2.0 & 485497 & 493384 & 487721 & 488867 & 4068.5406 & 0.8318 \\
120.00 & 2.4 & 609950 & 610547 & 608138 & 609545 & 1254.5274 & 0.2058 \\
\hline
\end{tabular}

Fonte: Autores, 2017. 
Avaliação da substituição do benzeno por ciclohexano como solvente residual na obtenção do álcool etílico absoluto.

TABELA 2 - Tabela de valores das áreas da curva de calibração, desvio padrão, desvio padrão relativo e média para o ciclohexano.

\section{Linearidade}

\begin{tabular}{|c|c|c|c|c|c|c|c|}
\hline $\begin{array}{c}\text { Concentraçäo } \\
(\%)\end{array}$ & $\begin{array}{c}\text { Concentraçāo } \\
\text { (mg/L) }\end{array}$ & $\begin{array}{c}\text { Curva } 1 \\
\text { Área }\end{array}$ & $\begin{array}{c}\text { Curva } 2 \\
\text { Área }\end{array}$ & $\begin{array}{c}\text { Curva } 3 \\
\text { Área }\end{array}$ & Média & DP & DPR $(\%)$ \\
\hline 1000 & 388.0 & 13157814 & 13084869 & 12998567 & 13080417 & 79716.806 & 0609 \\
\hline 20.00 & 776.0 & 26085702 & 26325573 & 25977489 & 26129588 & 178143491 & 0.682 \\
\hline 4000 & 1552.0 & 52786547 & 53002148 & 53100147 & 52962947 & 160433036 & 0.303 \\
\hline 6000 & 23280 & 81242781 & 80494798 & 81080239 & 80939273 & 393412.344 & 0.486 \\
\hline 8000 & 31040 & 106678728 & 107082861 & 106645867 & 106802485 & 243367.720 & 0.228 \\
\hline 100.00 & 3880.0 & 135769644 & 137864750 & 136284780 & 136633058 & 1095029133 & 0801 \\
\hline 12000 & 46560 & 162848624 & 161748514 & 163021041 & 162539393 & 690325358 & 0.425 \\
\hline
\end{tabular}

Fonte: Autores, 2017.

Pela a análise gráfica é possível verificar a linearidade da reação, em que se observam as concentrações da solução linear crescente, conforme mostrado nas Tabelas 1 e 2.
Foram obtidas análises de 9 concentrações, baixa, média e alta, contemplando o intervalo da linearidade do método. Nos testes foram feitas análises nas concentrações de $10 \%, 100 \%$ e $120 \%$, nos quais todos os critérios da RDC $n^{\circ} 166 / 17$ foram atendidos (TABELAS 3 e 4).

TABELA 3 - Exatidão das concentrações a 10\%, $100 \%$ e $120 \%$ para o benzeno.

\section{EXATIDAO}

\begin{tabular}{|c|c|c|c|c|c|c|c|c|c|}
\hline \multirow[b]{2}{*}{ Réplieas } & \multicolumn{3}{|c|}{$10.00 \%$} & \multicolumn{3}{|c|}{$100.00 \%$} & \multicolumn{3}{|c|}{$120.00 \%$} \\
\hline & $\begin{array}{c}\mathrm{mg} / \mathrm{L} \\
\text { Recuperado }\end{array}$ & $\%$ Real & $\begin{array}{c}\% \\
\text { Recuperada }\end{array}$ & $\begin{array}{c}\mathrm{mg} / \mathrm{L} \\
\text { Recuperado }\end{array}$ & $\%$ Real & $\begin{array}{c}\% \\
\text { Recuperada }\end{array}$ & $\begin{array}{c}\text { mg/L } \\
\text { Recuperado }\end{array}$ & \% Real & $\begin{array}{c}\text { \% } \\
\text { Recuperada }\end{array}$ \\
\hline 1 & 0.201 & $10.050 \%$ & $100.600 \%$ & 1.986 & $99.310 \%$ & $99,310 \%$ & 2.495 & $124.770 \%$ & $103.975 \%$ \\
\hline 2 & 0.199 & $9.970 \%$ & $99.700 \%$ & 2.018 & $100.920 \%$ & $100,920 \%$ & 2.498 & $124.890 \%$ & $104.075 \%$ \\
\hline 3 & 0.219 & $10.970 \%$ & $109.700 \%$ & 1.995 & $99.770 \%$ & $99.770 \%$ & 2.488 & $124.400 \%$ & $103.667 \%$ \\
\hline MÉDIA & 0,207 & $10.333 \%$ & $103.333 \%$ & 2000 & $100.000 \%$ & $100.000 \%$ & 2.494 & $124.687 \%$ & $103,906 \%$ \\
\hline DP & & 0.01 & & & 0.02 & & & 0.01 & \\
\hline DPR $(\%)$ & & 5.35 & & & 0.83 & & & 0.20 & \\
\hline
\end{tabular}

Fonte: Autores, 2017.

TABELA 4 - Exatidão das concentrações a 10\%, 100\% e 120\% para o ciclohexano.

\section{EXATIDAO}

\begin{tabular}{|c|c|c|c|c|c|c|c|c|c|}
\hline \multirow[b]{2}{*}{ Réplicas } & \multicolumn{3}{|c|}{$10.00 \%$} & \multicolumn{3}{|c|}{$100.00 \%$} & \multicolumn{3}{|c|}{$120.00 \%$} \\
\hline & $\begin{array}{c}\mathrm{mg} / \mathrm{L} \\
\text { Recuperado }\end{array}$ & $\%$ Real & $\begin{array}{c}\% \\
\text { Recuperada }\end{array}$ & $\begin{array}{c}\mathrm{mg} / \mathrm{L} \\
\text { Recuperado }\end{array}$ & $\%$ Real & $\begin{array}{c}\% \\
\text { Recuperada }\end{array}$ & $\begin{array}{c}\mathrm{mg} / \mathrm{L} \\
\text { Recuperado }\end{array}$ & $\%$ Real & $\begin{array}{c}\% \\
\text { Recuperada }\end{array}$ \\
\hline 1 & 394,208 & $10.160 \%$ & $101.600 \%$ & 3892.028 & $100.310 \%$ & $100.310 \%$ & 4763.476 & $122.770 \%$ & $102.308 \%$ \\
\hline 2 & 415.160 & $10.700 \%$ & $107.000 \%$ & 3915.696 & $100.920 \%$ & $100.920 \%$ & 4729.332 & $121.890 \%$ & $101.575 \%$ \\
\hline 3 & 398.476 & $10.270 \%$ & $102.700 \%$ & 3878.836 & $99.970 \%$ & $99.970 \%$ & 4749.120 & $122.400 \%$ & $102.000 \%$ \\
\hline MÉDIA & 402.615 & $10.377 \%$ & $103.767 \%$ & 3895.520 & $100.400 \%$ & $100.400 \%$ & 4747.309 & $122.353 \%$ & $101.961 \%$ \\
\hline DP & & 11.07 & & & 18.68 & & & 17.14 & \\
\hline DPR (\%) & & 2.75 & & & 0.48 & & & 0.36 & \\
\hline
\end{tabular}

Fonte: Autores, 2017. 
Avaliação da substituição do benzeno por ciclohexano como solvente residual na obtenção do álcool etílico absoluto.

Em consonância ao artigo 38 da RDC no 166/17, foram analisadas 6 réplicas na concentração de $100 \%$, equivalente a $2 \mathrm{mg} / \mathrm{L}$, seguindo os critérios de aceitação para o desvio padrão relativo. A precisão foi aprovada demonstrando resultados próximos, o que comprovou a precisão do método (Tabelas 5 e 6).

TABELA 5 - Resultados obtidos na avaliação da precisão do método utilizado para o benzeno.

\section{PRECISĀO}

\begin{tabular}{cc}
\hline Róplicas & Concentraçă $100 \%$ (2 ming) \\
\hline 1 & 99.310 \\
2 & 100.920 \\
3 & 99.770 \\
4 & 101.120 \\
5 & 99.240 \\
6 & 100.130 \\
Média & 100.082 \\
Desvio padrāo & 0.729 \\
Desvio padrăo relativo (\%) & 0.797 \\
Variância & 0.637 \\
\hline
\end{tabular}

Fonte: Autores, 2017.

TABELA 6 - Resultados obtidos na avaliação da precisão do método utilizado para o ciclohexano.

PRECISĀO

\begin{tabular}{cc}
\hline Réplicas & Concentraçäo 100\% (2 mg/L) \\
\hline 1 & 101.020 \\
2 & 100.220 \\
3 & 100.770 \\
4 & 100.120 \\
5 & 99.740 \\
6 & 99.830 \\
Média & 100.283 \\
Desvio padräo & 0.467 \\
Desvio padräo relativo (\%) & 0.511 \\
Variåncia & 0.262 \\
\hline
\end{tabular}

Fonte: Autores, 2017.

Análise dos picos cromatográficos

De acordo com os resultados obtidos nos cromatogramas, não foram detectados picos de benzeno nas duas amostras pesquisadas (FIGURAS 5 e 6), o tempo de retenção, segundo o padrão de benzeno, foi de 22 minutos, e não foi possível quantificá-lo devido à metodologia com limite de identificação de $2 \mathrm{mg} / \mathrm{L}^{22,23}$ (FIGURA 4). É possível observar picos de outras impurezas não identificadas nas duas amostras, porém foram detectados ciclohexano em um tempo de retenção de 11 minutos indicando a substituição do benzeno por ciclohexano em ambos fabricantes. 


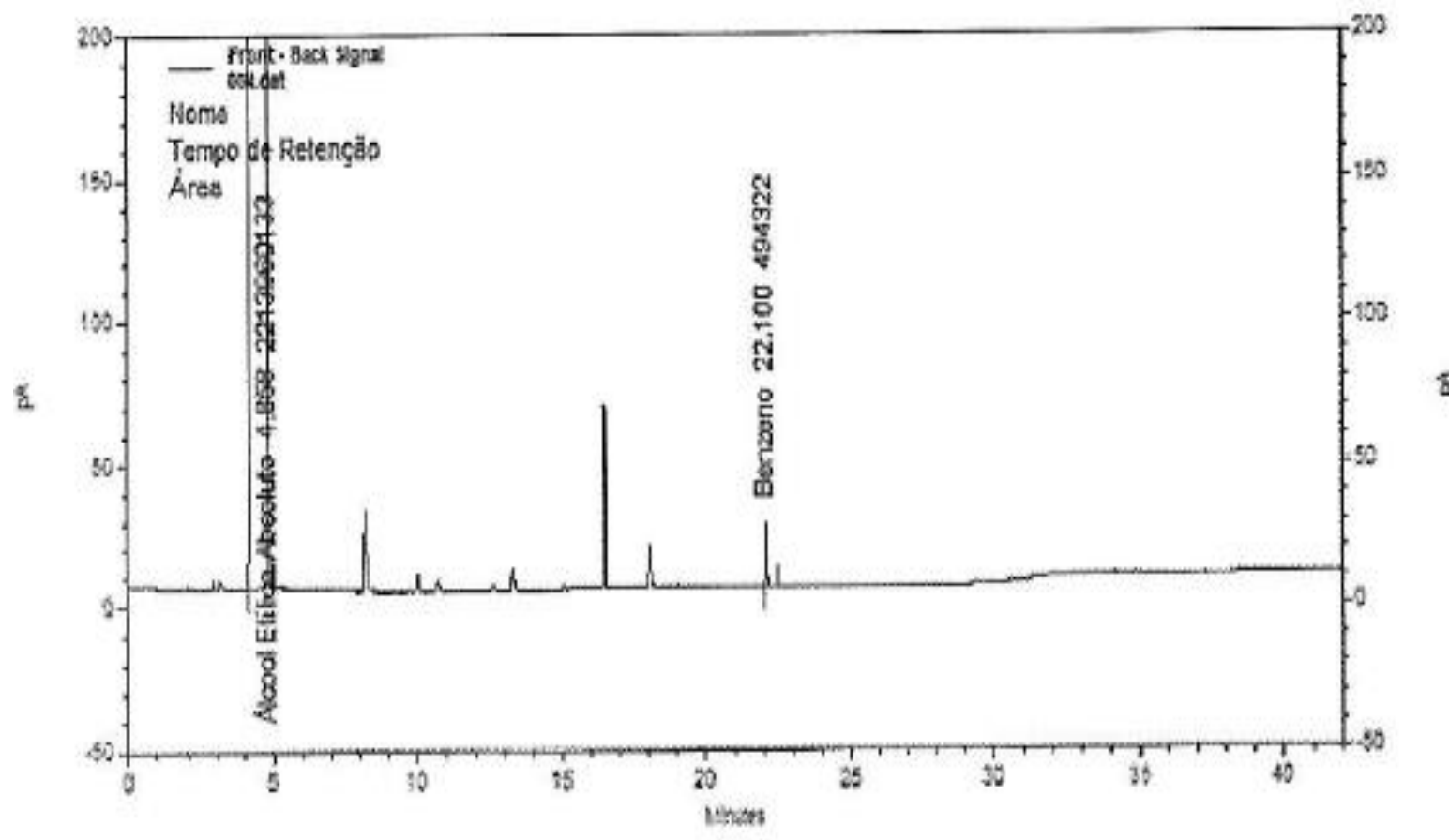

FIGURA 4 - Picos Cromatográficos do padrão de benzeno a 2 mg/L e sua área e tempo de retenção.

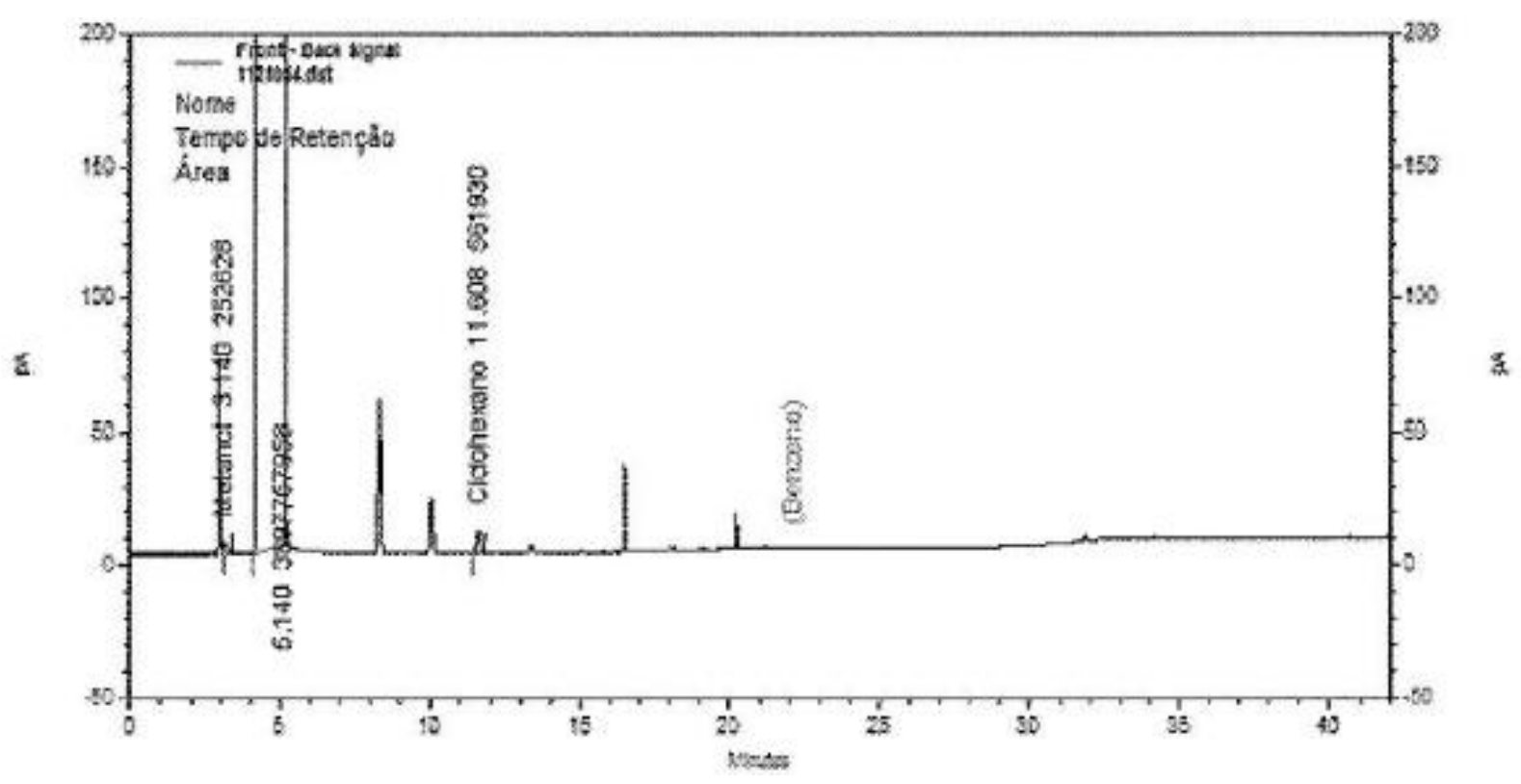

FIGURA 5 - Picos Cromatográficos do fabricante 1, não houve detecção de benzeno. 


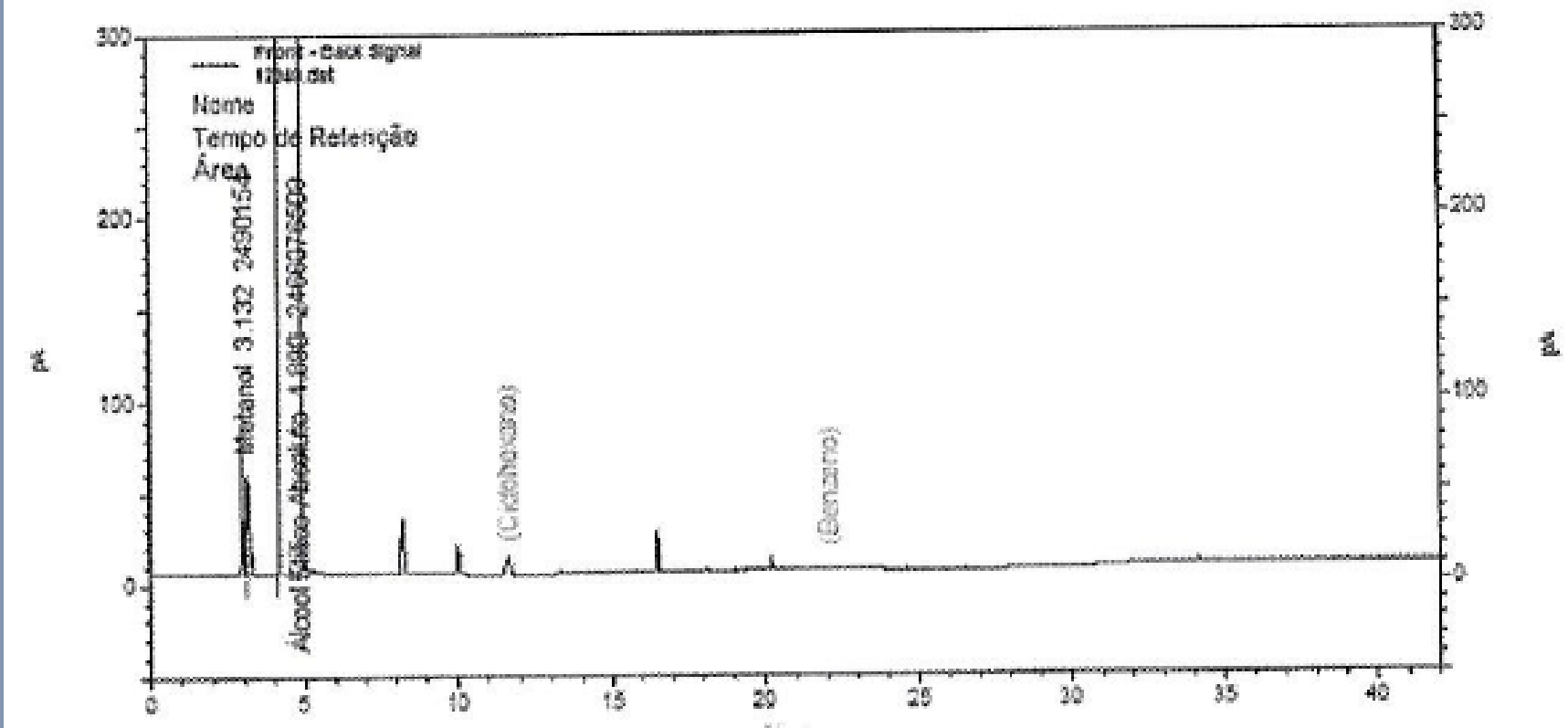

FIGURA 6 - Picos Cromatográficos do fabricante 2, não houve detecção de benzeno.

Lopes $^{24}$ atenta para o fato de que a obtenção do álcool absoluto por meio da destilação azeotrópica, que ainda é utilizada no Brasil, pode resultar em resíduos orgânicos de benzeno ou outros solventes utilizados em sua desidratação, principalmente quando são produzidos em larga escala por meio das grandes colunas de destilação. De acordo com o IPVS (índice perigoso à vida e à saúde), proposto pelo The National Institute for Occupational Safety and Health (NIOSH), o limite do solvente benzeno é de $500 \mathrm{mg} / \mathrm{L}$, mas essa concentração dificilmente seria encontrada no álcool, devido ao controle de qualidade exigido pela ANVISA. Essa afirmação pode ser comprovada nos resultados apresentados pelos ensaios realizados nesta pesquisa.

Neste estudo, foi possível detectar picos de ciclohexano no cromatograma de ambos os fabricantes. Os resultados comprovam que, atualmente, novas formas de obtenção do álcool absoluto têm sido utilizadas, nas quais o benzeno é substituído por solventes com menor toxicidade como o ciclohexano. ${ }^{23,25}$
Para realizar um teste comparativo, foram feitas injeções utilizando o solvente ciclohexano para validar que o pico detectado refere a esse composto (FIGURA 7) no tempo de retenção de 11 minutos, o que de fato indicou que houve a substituição do benzeno por ciclohexano no processo de destilação das amostras analisadas dos dois fabricantes. 


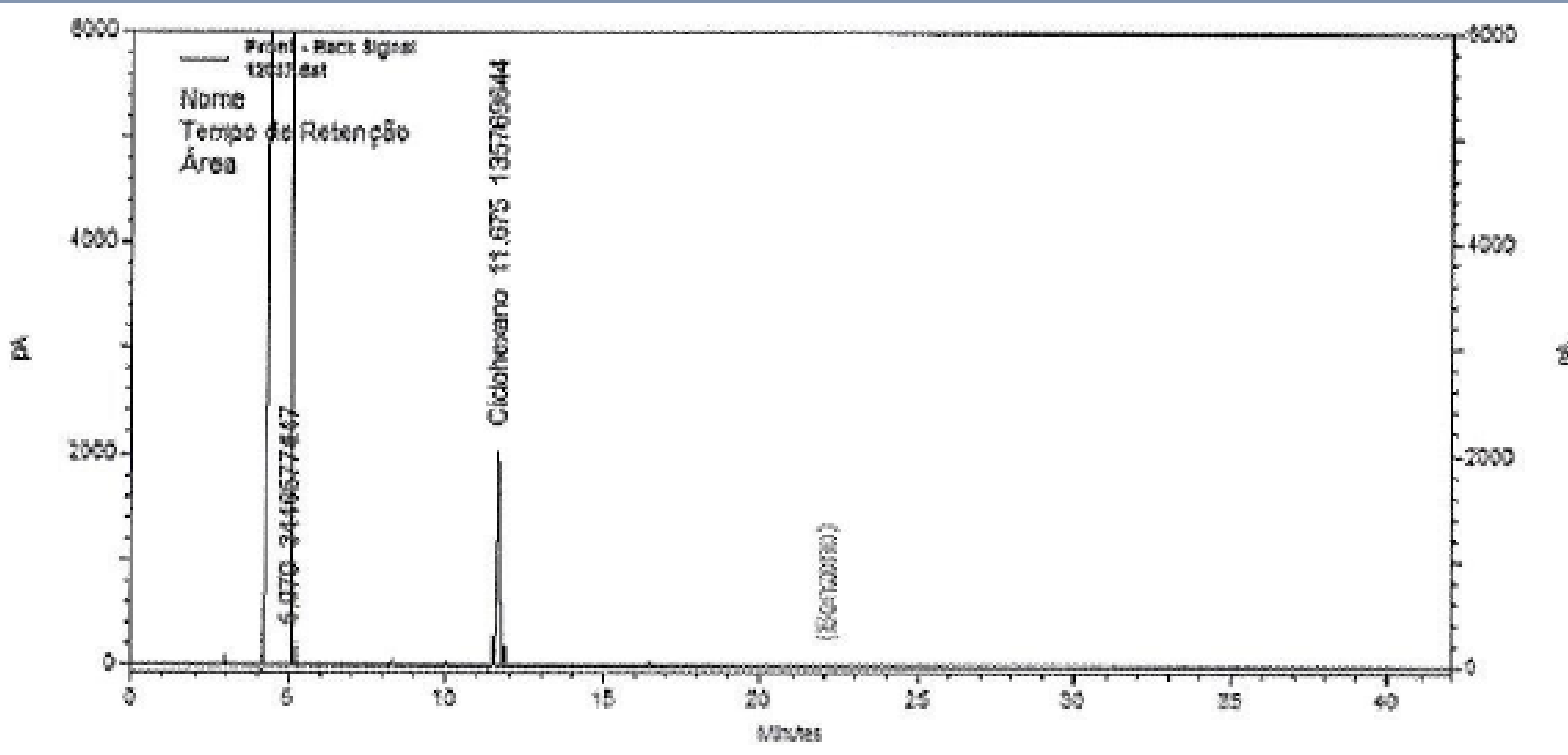

FIGURA 7 - Padrão de ciclohexano eluindo no mesmo tempo de retenção que a impureza não identificada nas amostras dos fabricantes 1 e 2.

O ciclohexano, quando substituído pelo benzeno na destilação do álcool anidro, traz um produto acabado mais seguro ao consumidor.

Todavia, para garantir a qualidade do álcool nesse quesito, a cromatografia gasosa (CG) é altamente eficiente, pois é uma técnica poderosa de separação que possibilita a detecção de analitos virtualmente puros. Isso quer dizer que a CG prepara de forma admirável os analitos para identificação e quantificação, mas a viabilização da análise depende de um método adequado de preparo da amostra. ${ }^{26}$

Em consideração ao teste realizado, foi possível reconhecer a sua importância em relação à qualidade e à segurança da saúde pública, por trazer informações, muitas vezes, desconhecidas ao consumidor, e promover a garantia da qualidade ofertada pelas indústrias de álcool etílico absoluto, comercializados em drogarias das cidades do centro-oeste mineiro.

\section{Limitações do estudo}

O estudo realizado apresentou limitações quanto aos lotes e fabricantes das amostras testadas. A limitação dos lotes e fabricantes das amostras se refere à pequena quantidade de amostragens e marcas encontradas. Foi realizada a análise apenas de um lote por fabricante de álcool permitindo, assim, considerar os resultados encontrados somente para os lotes e fabricantes em questão.

\section{Conclusão}

Os resultados do teste realizado foram satisfatórios, assim como a técnica utilizada. Todos os fabricantes avaliados apresentaram-se dentro dos padrões de qualidade, comprovando a sua segurança em relação ao benzeno, ou seja, adequados para o uso. Porém foi detectado a presença de ciclohexano em ambos fabricantes que afirma a substituição do benzeno pelo mesmo no processo de desidratação do álcool em quantidades permitidas.

\section{Declaração de conflitos de interesses}

Os autores deste artigo afirmam que não houve nenhuma situação de conflito de interesse, tais como propostas de financiamento, emissão de pareceres, promoções ou participação em comitês consultivos ou diretivos, entre outras, que pudessem influenciar no desenvolvimento do trabalho.

\section{Agradecimentos}

Ao professor e orientador Wilson Rodrigues Braz e a indústria farmacêutica parceira que nos disponibilizou o laboratório com equipamentos e materiais para a realização desta pesquisa. 


\section{Referências}

1 - UNIÃO DA INDÚSTRIA DE CANA-DE-AÇÚCAR (UNICA). Produção e Uso do Etanol Combustível no Brasil: respostas às questões mais frequentes. São Paulo: UNICA, 2007. 70 p. Disponível em: <http://www.ie.ufrj.br/infosucro/biblioteca/bic_Unica_Pr od ucaoUsoEtanol. pdf $>$. Acesso em: 28 out. 2017.

2 - BARRETO, T. V.; COÊLHO, A. C. D. Destilação. In: SANTOS, F.; BORÉM, A.; CALDAS, C. Cana-deaçúcar: bioenergia, açúcar e álcool - tecnologias e perspectivas. 22. ed. Viçosa: UFV, 2010. p. 15-16. Acesso em: 28 out. 2017.

3 - SEABRA, J. E. A. Avaliação técnico-econômica de opções para $o$ aproveitamento integral da biomassa de cana no Brasil. Tese (Doutorado em Planejamento de Sistemas Energéticos) - Escola de Engenharia, Universidade Estadual de Campinas, São Paulo, 2008.

4 - PROCESSO DE PRODUÇÃO DO ETANOL Destilação. Escola de Engenharia de Lorena/Universidade de São Paulo (EEL-USP). Notas de aula. São Paulo, 2014. Disponível em: <http://sistemas.eel.usp.br/docentes/arquivos/5840855/L OQ4023/Processoproducaodee tanol2014.pdf>. Acesso em: 06 ago. 2017.

5 - CASTRO, H. F. Indústria alcooleira. Apostila 2 da disciplina Processos Químicos Industriais II, 2011. Disponível <http://sistemas.eel.usp.br/docentes/arquivos/5840556 /434/Apostila2IndustriaAlcooleira-2011.pdf>. Acesso em: 10 ago. 2017.

6 - CONFEDERAÇÃO NACIONAL DA INDÚSTRIA. Consolidação da legislação sobre o benzeno. - Brasília: CNI/SESI, 2012. Disponível em: <http://www.protecao.com.br/upload

/protecao_materiaarquivo/495.pdf>. Acesso em: 21 nov. 2017.

7- BRASIL. Ministério do Trabalho e Emprego. Portaria Interministerial $\mathrm{n}^{\circ} 775$, de 28 de abril de 2004. Proíbe a comercialização de produtos acabados que contenham "benzeno" em sua composição, admitindo, porém, alguns percentuais. Disponível em: <http://www.anest .org.br/wp-

content/uploads/sites/2/2017/02/leg_portaria_023.pdf>. Acesso em: 21 nov. 2017.

8 - VOLLHARDT, P.; SCHORE, N. E. Química Orgânica. 6. ed. Porto Alegre: Bookman, 2013. p. 627.

9 - BRASIL. Ministério da Saúde. Portaria GM/MS n ${ }^{\circ}$ 776, de 28 de abril de 2004. Dispõe sobre a regulamentação dos procedimentos relativos à vigilância da saúde dos trabalhadores expostos ao benzeno e dá outras providências. Diário Oficial [da] República Federativa do Brasil, Brasília, DF, 29 abr. 2004. Disponível em: <http://www.saude.mt.gov.br/cosat/ar quivo/1838/sobre-benzeno>. Acesso em: 10 ago. 2017.

10 - INTERNATIONAL PROGRAMME ON CHEMICAL SAFETY (IPCS). Environmental Health Criteria 150 - Benzene. Geneva: IPCS, World Health Organization, 1993. Disponível em: <http://www.inchem.org/pages/ehc.html>. Acesso em: 29 out. 2017.
11 - OGA, S. Fundamentos de toxicologia. São Paulo: Atheneu, 2005.

12 - ARCURI, A. S. A.; COSTA, D. F.; POSSEBON, J. Efeitos da exposição ao benzeno para a saúde. v. $1, \mathrm{n}$. 1. São Paulo: Fundacentro, 2012. 52 p.

13 - COSTA, M. A. F.; COSTA, M. F. B. Benzeno: uma questão de saúde pública. Interciência. v. 27, n. 4, 2012, p. 201-204.

14 - SANTOS, A. A. M. Higienização das mãos no controle das infecções em serviços de saúde. Revista de Administração em Saúde. v. 14, n. 15, abr-jun/2002, p. $10-14$.

15 - BRASIL. Agência Nacional de Vigilância Sanitária. Resolução RDC n 46, de 20 de fevereiro de 2002, que dispõe sobre Regulamento Técnico para álcool etílico hidratado, em todas as graduações, e álcool etílico anidro comercializados por atacadistas e varejistas. Diário Oficial [da] República Federativa do Brasil, Brasília, DF, 21 de fevereiro de 2002.

16 - BRASIL. Agência Nacional de Vigilância Sanitária. Resolução RDC no 53, de 04 de dezembro de 2015, que estabelece parâmetros para a notificação, identificação e qualificação de produtos de degradação em medicamentos com substâncias ativas sintéticas e semissintéticas, classificados como novos, genéricos e similares, e dá outras providências. Diário Oficial [da] República Federativa do Brasil, Brasília, DF, 08 de dezembro de 2015.

17 - BRASIL. Agência Nacional de Vigilância Sanitária. Resolução RDC no 252, de 16 de setembro de 2003, que dispõe sobre Regulamento Técnico para o uso de benzeno. Diário Oficial [da] República Federativa do Brasil, Brasília, DF, 17 de setembro de 2003.

18 - BRASIL. Agência Nacional de Vigilância Sanitária. Resolução RDC no 166, de 24 de julho de 2017, que dispõe sobre a validação de métodos analíticos e dá outras providências. Diário Oficial [da] República Federativa do Brasil, Brasília, DF, 25 de julho de 2017.

19 - COLLINS, C. H.; BRAGA, G. L.; BONATO, P. S. Fundamentos de cromatografia. Campinas, SP: UNICAMP, 2006.

20 - UNITED STATES PHARMACOPEIAL CONVENTION (USP). USP 40 NF 35. Pharmabooks, 2017, p. 2616.

21 - LEITE, F. Validação em análise química. Campinas, SP: Átomo, 2008.

22 - ICH EXPERT WORKING GROUP. ICH Harmonised Tripartite Guideline. Impurities: Guideline for Residual Solvents. Q3C (R5). v. 4, fev. 2011. Disponível em: <http://www.ich .org/fileadmin/Public_Web_Site/ICH_Products/Guidelin es/Quality/Q3C/Step4/Q3C_R5_Step4.pdf>. Acesso em: 12 set. 2017.

23 - CHIEPPE JUNIOR, J. B. Tecnologia e fabricação do álcool. Inhumas: IFG; Santa Maria: Universidade Federal de Santa Maria, 2012. 74 p. Disponível em: $<$ http://redeetec.mec.gov

.br/images/stories/pdf/eixo_prd_industr/tec_acucar_alcoo 1>. Acesso em: 06 out. 2017.

24 - LOPES, J. J. C. A cana-de-açúcar como matériaprima para produção de açúcar e álcool. 1. ed. Araras, SP: Centro de Ciências Agrárias - campus Araras da 
Avaliação da substituição do benzeno por ciclohexano como solvente residual na obtenção do álcool etílico absoluto.

Universidade Federal de São Carlos, 2009. 64 p. (Apostila) A.

25 - FIGUEIRÊDO, M. F. Obtenção de etanol anidro via destilação extrativa: simulação e otimização. Dissertação (Mestrado em Engenharia Química) Universidade Federal de Campina Grande. Campina
Grande, PB, out. 2009. Disponível em: <http://livros01.livros gratis.com.br/cp110875.pdf>. Acesso em: 08 ago. 2017.

26 - PAWLISZYN, J. Solid Phase Microextraction: Theory and Practice. Nova York: Wiley-VHC, 1997. p. 3. 